\title{
The Interaction Between Non-Coding RNAs and Calcium Binding Proteins
}

\author{
Soudeh Ghafouri-Fard ${ }^{1}$, Jamal Majidpoor ${ }^{2}$, Hamed Shoorei ${ }^{3}$, \\ Bashdar Mahmud Hussen ${ }^{4,5}$, Hazha Hadayat Jamal ${ }^{6}$, Aria Baniahmad ${ }^{7}$, \\ Mohammad Taheri ${ }^{7,8 *}$ and Majid Mokhtari ${ }^{9 *}$
}

\begin{abstract}
1 Department of Medical Genetics, School of Medicine, Shahid Beheshti University of Medical Sciences, Tehran, Iran, 2 Department of Anatomy, Faculty of Medicine, Infectious Diseases Research Center, Gonabad University of Medical Sciences, Gonabad, Iran, ${ }^{3}$ Department of Anatomical Sciences, Faculty of Medicine, Birjand University of Medical Sciences, Birjand, Iran, ${ }^{4}$ Department of Pharmacognosy, College of Pharmacy, Hawler Medical University, Erbil, Iraq, ${ }^{5}$ Center of Research and Strategic Studies, Lebanese French University, Erbil, Iraq, ${ }^{6}$ Department of Biology, College of Education, Salahaddin University-Erbil, Erbil, Iraq, ${ }^{7}$ Institute of Human Genetics, Jena University Hospital, Jena, Germany, ${ }^{8}$ Urology and Nephrology Research Center, Shahid Beheshti University of Medical Sciences, Tehran, Iran, ${ }^{9}$ Skull Base Research Center, Loghman Hakim Hospital, Shahid Beheshti University of Medical Sciences, Tehran, Iran
\end{abstract}

OPEN ACCESS

Edited by:

Jing Zhang,

Shanghai Jiao Tong University, China

Reviewed by:

Zhaofeng Liang,

Jiangsu University, China

Mu Hao,

Peking Union Medical College Hospital (CAMS), China

*Correspondence:

Mohammad Taheri

Mohammad.taheri@uni-jena.de

Majid Mokhtari

majimokh@gmail.com

Specialty section:

This article was submitted to Molecular and Cellular Oncology,

a section of the journal

Frontiers in Oncology

Received: 04 January 2022 Accepted: 14 February 2022

Published: 04 March 2022

Citation:

Ghafouri-Fard S, Majidpoor J, Shoorei H, Hussen BM, Hadayat Jamal H, Baniahmad A, Taheri $M$ and Mokhtari $M$ (2022) The Interaction Between Non-Coding RNAs and Calcium Binding Proteins.

Front. Oncol. 12:848376.

doi: 10.3389/fonc.2022.848376
Calcium binding proteins (CBP) are a group of proteins mediating the effects of calcium on cellular functions. These proteins can regulate calcium levels inside the cells and contribute in several cellular functions through transporting this ion across cell membranes or decoding related signals. Recent studies have shown that several noncoding RNAs interact with CBPs to affect their expression or activity. The interactions between these transcripts and CBPs have implications in the pathoetiology of human disorders, including both neoplastic and non-neoplastic conditions. In the current review, we describe the interactions between three classes of non-coding RNAs (long non-coding RNAs, circular RNAs, and microRNAs) and a number of CBPs, particularly CAB39, S100A1, S100A4, S100A7 and S100P. This kind of interaction has been verified in different pathological contexts such as drug-induced cardiotoxicity, osteoblasts cytotoxicity, acute lung injury, myocardial ischemia/reperfusion injury, proliferative diabetic retinopathy, glomerulonephritis, as well as a wide array of neoplastic conditions.

Keywords: non-coding RNA, calcium binding protein, IncRNA, circRNA, miRNA

\section{INTRODUCTION}

Calcium is an important second messenger in cells whose effects are largely dependent on a number of diverse proteins, being named as calcium binding proteins (CBP), accordingly. These proteins can bind this ion in their certain domains. CBPs can regulate calcium levels inside the cells and contribute in several cellular functions through transporting this ion across cell membranes or decoding related signals (1). Based on the presence of the structural EF-hand domain, intracellular CBPs can be classified into two main classes, i.e., those containing this domain and those lacking this domain. Parvalbumin, calmodulin, S100 proteins and calcineurin are examples of the former class, while calreticulin, calsequestrin, annexins, protein kinase $\mathrm{C}(\mathrm{PKC})$ and sinaptotagmin are examples of the latter (1). Extracellular CBP has six main classes, based on the presence of EF-hand, EGF-like, $\gamma$-carboxyl glutamic acid (GLA)-rich, cadherin, and calcium-dependent (C)-type lectin-like 
domains or calcium binding pockets of family C G-proteincoupled receptors (1). Extracellular CBPs are incessantly surrounded by a concentration of $10^{-3} \mathrm{M}$ calcium which contributes in the activation or stabilization of specific enzymes acting as protease, nuclease, or lipase. On the other hand, intracellular CBPs, which act as muscle contraction, respond to an upsurge in calcium concentrations from $10^{-7}$ to $10^{-6} \mathrm{M}$ (2). Recent studies have shown that several non-coding RNAs interact with CBPs to affect their expression or activity. The interactions between these transcripts and CBPs have implications in the pathoetiology of human disorders, including both neoplastic and non-neoplastic conditions. In the current review, we describe the interactions between three classes of non-coding RNAs (long non-coding RNAs (lncRNAs), circular RNAs [circRNAs) and microRNAs (miRNAs)] and CBPs.

\section{NON-CODING RNAs AND CAB39}

Calcium-binding protein 39 (CAB39) is functionally associated with the Serine/Threonine Kinase STK11 and STRAD (3). This protein also promotes the construction of STK11/STRAD complexes and induces catalytic activity of STK11 (3). This protein has been found to affect the process of doxorubicininduced cardiac injury. Experiments in an animal model of doxorubicin-induced cardiotoxicity have shown up-regulation of miR-451 levels. Suppression of miR-451 expression has reduced doxorubicin-associated whole-body wasting and cardiac atrophy, decreased heart damage, amended heart function, and enhanced contractile function of cardiomyocytes. Functionally, miR-451 suppression has led to enhancement of Cab39 levels and induced activity of AMPK signaling (Figure 1). Thus, Cab39 has been identified as the target of miR-451 through which this miRNA affects cardiac toxicity (4). Another study to find the mechanism of osteoblast cytoprotection has reported miR-107 as a CAB39-targeting miRNA. Functional experiments in OB-6 human osteoblastic cells have shown direct binding of this miRNA with CAB39 mRNA. Both wild-type miR-107 mimics and pre-miR-107-containing lentiviruses could inhibit CAB39 expression in osteoblasts. On the other hand, miR-107 antagonism could increase CAB39 expression, leading to activation of AMPK cascade. Suppression of miR-107 has significantly decreased dexamethasone-induced apoptosis in

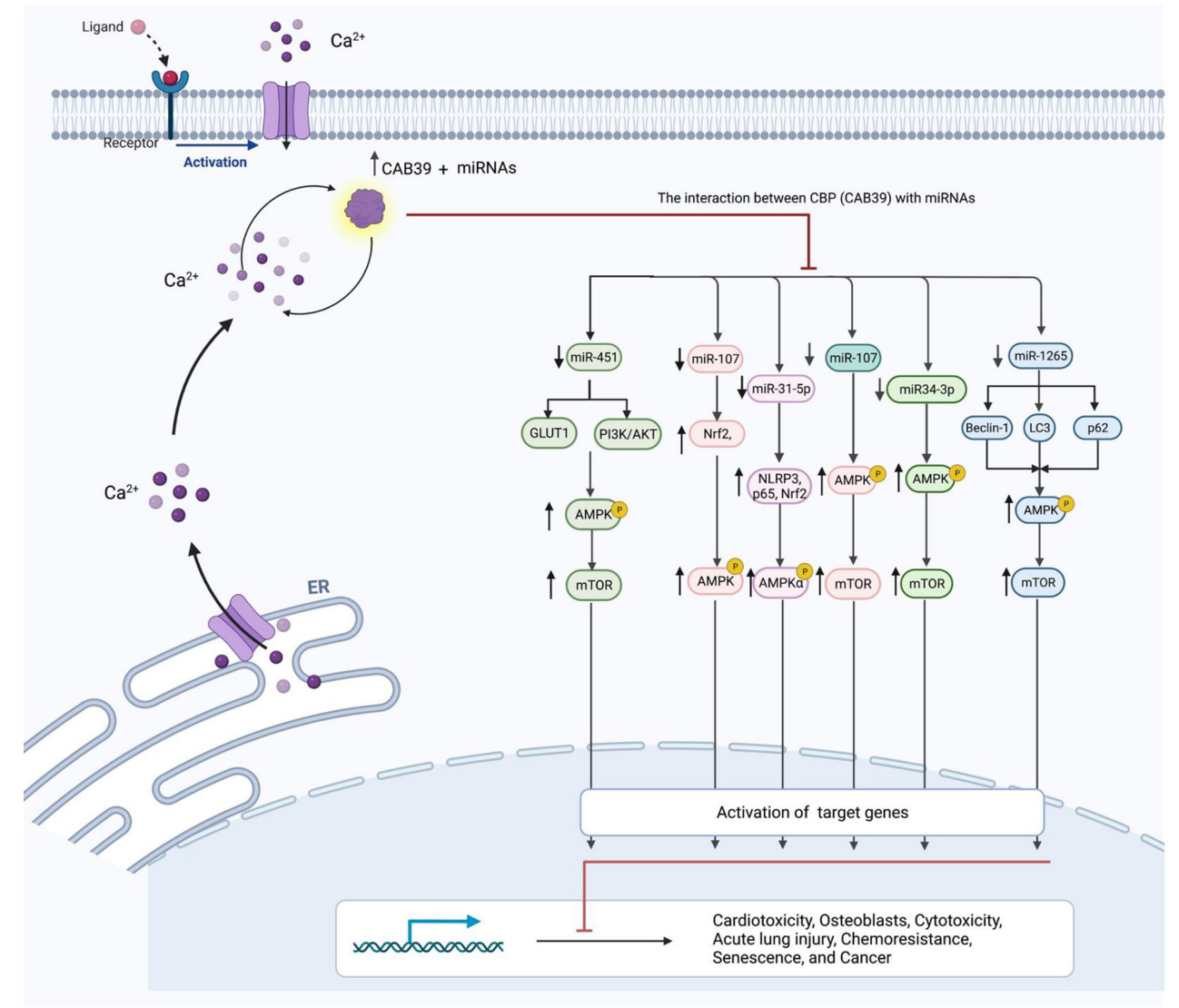

FIGURE 1 | The connection between CAB39 and miRNAs, as well as their role in human diseases. Inhibition of miRNA has resulted in increased CAB39 levels and increased activity of AMPK pathway. Cab39 has therefore been found as a miRNAs target, and these miRNAs modulate cardiotoxicity, osteoblasts, cytotoxicity, acute lung damage, chemoresistance, senescence, and cancer development through this RNA. 
OB-6 cells and human osteoblasts. Moreover, antagomiR-107 could activate AMPK downstream Nrf2 cascade to suppress dexamethasone-associated oxidative injury (5). The interaction between miRNAs and CAB39 has also been implicated in the pathogenesis of acute lung injury. The CAB39-interacting miR-31-5p has been shown to be up-regulated in mice lung tissues upon injection of lipopolysaccharide. miR-31-5p silencing has relieved, while miR-31-5p mimic has aggravated lipopolysaccharide-induced inflammatory responses, oxidative injury, and pulmonary injury in vivo and in vitro. Functionally, miR-31-5p silencing has induced protective impact of AMPKo. In fact, Cab39 has an essential role in activation of AMPK $\alpha$ and protective effects of miR-31-5p antagomir (6). The interaction between miRNAs and CAB39 has an important role in the pathogenesis of cancers. For instance, miR-1265 can regulate cell proliferation and apoptosis in gastric cancer cells by targeting CAB39. miR-1265-mediated suppression of CAB39 interferes with oncogenic autophagy through modulation of AMPK/mTOR (7). On the other hand, miR-107-mediated suppression of CAB39 and subsequent activation of AMPK/mTOR signaling confers chemoresistance to colorectal cancer (8). Table 1 summarizes the role of CAB39-interacting miRNAs in the pathogenesis of different disorders.

CircGSK3B (hsa_circ_0003763) is a circRNA that has indirect interaction with CAB39. This circRNA has been found to be upregulated in hepatocellular cancer tissues and cell lines. In addition, expression levels of circGSK3B have been correlated with tumor bulk and vascular invasion. Functional studies have indicated the role of circGSK3B in the enhancement of proliferation, migratory potential, and invasiveness of hepatocellular carcinoma. Mechanistically, circGSK3B sponges miR-1265 to up-regulate expression of CAB39 (Figure 2). This circRNA has a role in reprogramming of glutamine metabolism. Taken together, circGSK3B/miR-1265/CAB39 axis has a role in enhancing proliferation, migration, invasion of this kind of cancer (11). HOTAIR is an example of lncRNAs that activates AMPKo via EZH2/miR-451/CAB39 axis regulation. CAB39 is involved in regulation of oxidative stress and cardiac myocyte apoptosis during ischemia/reperfusion injury (12). Table 2 summarizes CAB39-interacting lncRNAs/circRNAs.

\section{NON-CODING RNAs AND S100A4}

S100A4 is a member of the S100 CBP family, which is produced by tumor cells as well as stromal cells. S100 proteins are localized in the cytoplasm and/or nucleus of several kinds of cells and participate in the regulation of cell cycle transition and differentiation. The genes coding members of S100 family are clustered on chromosome 1q21 (13). This CBP has been shown to support tumorigenesis through stimulation of angiogenesis. A number of miRNAs have been shown to inhibit the expression of S100A4. For instance, miR-187-3p by targeting S100A4 could inhibit the metastasis and epithelial-mesenchymal transition (EMT) of hepatocellular carcinoma (14). Expression of S100A4 has been shown to be increased in ovarian cancer in association with clinical stage of these patients. Down-regulation of this CBP

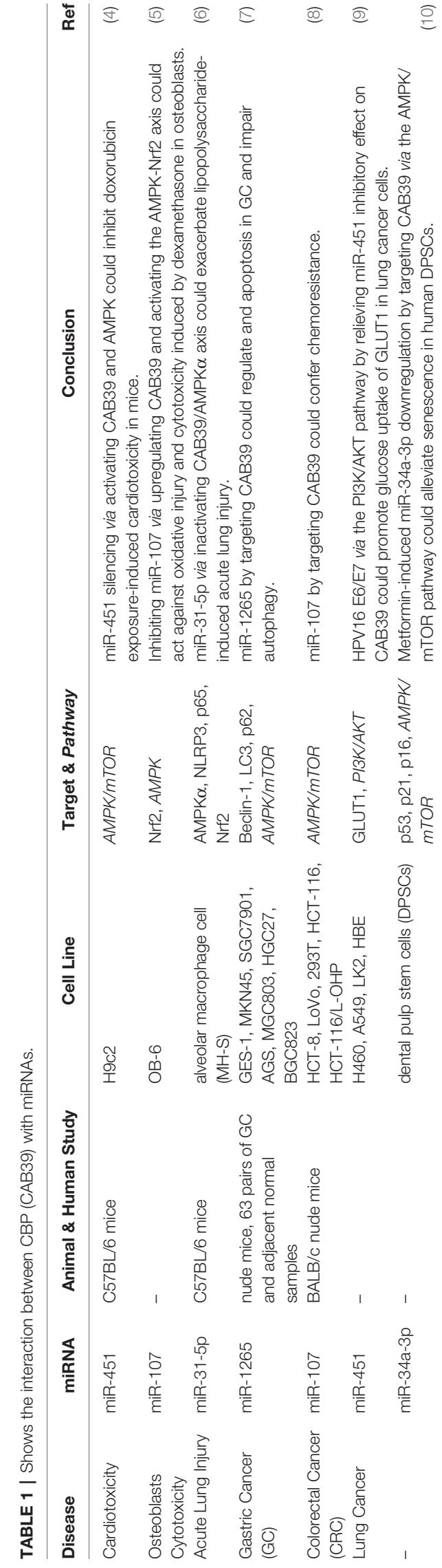




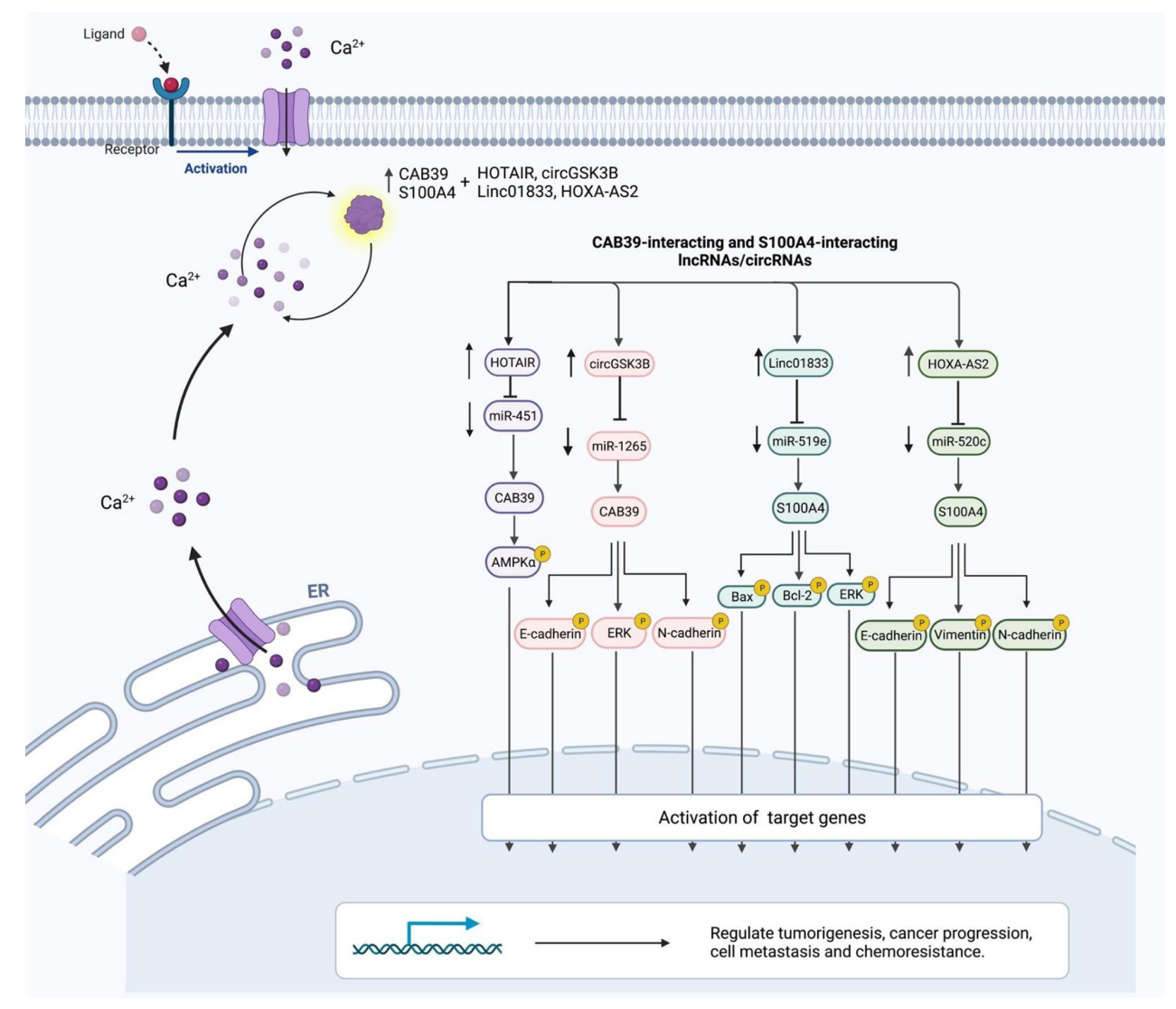

FIGURE 2 | Interaction between CBPs (CAB39 and S100A4) and IncRNAs/circRNAs with their contribution in human disorders.

TABLE 2 | CAB39-interacting IncRNAs/circRNAs.

\begin{tabular}{|c|c|c|c|c|c|c|}
\hline Disease & $\begin{array}{l}\text { IncRNA/ } \\
\text { circRNA }\end{array}$ & $\begin{array}{c}\text { Animal \& } \\
\text { Human } \\
\text { Study }\end{array}$ & Cell Line & Target \& Pathway & Conclusion & Ref \\
\hline Myocardial I/R Injury & HOTAIR & $\begin{array}{l}\text { C57BL/6 } \\
\text { mice }\end{array}$ & $\mathrm{H} 9 \mathrm{c} 2$ & $\begin{array}{l}\text { AMPK } \alpha, \text { BRD4, Bax, } \\
\text { Bcl-2, SIRT1, MnSOD, } \\
\text { Catalase, AKT }\end{array}$ & $\begin{array}{l}\text { HOTAIR could activate AMPK } \alpha \text { via regulating the EZH2/miR-451/ } \\
\text { CAB39 axis, therefore, it is involved in regulation of oxidative stress } \\
\text { and cardiac myocyte apoptosis during I/R injury. }\end{array}$ & (12) \\
\hline
\end{tabular}

has reduced the mobility of ovarian cancer cells and their metastatic ability, while up-regulation of S100A4 has increased the invasive aptitude of these cells. miR-296 has been identified as an important upstream regulator of this CBP (Figure 3). Dysregulation of miR-296/S100A4 axis could facilitate EMT (15). Another study in bladder cancer has revealed that miR-149-3p could inhibit proliferation, migration, and invasion of malignant cells through targeting S100A4 (16). In colorectal cancer cells, miR325-3p/S100A4 (17), miR-520c/S100A4 (18) and miR-296/S100A4 (19) have been identified as molecular axes that affect carcinogenesis. Table 3 shows S100A4-interacting miRNAs.

A number of IncRNAs have been found to affect miRNA/S100A4 axes. These lncRNAs mainly act as molecular sponges for S100A4- interacting miRNAs, thus releasing S100A4 from inhibitory effects of these miRNAs. For instance, HOXA-AS2 through regulating miR520c-3p/S100A4 (23) and miR-520c-3p/S100A4 (24) axes could affect pathogenesis of papillary thyroid cancer and acute myeloid leukemia, respectively. Moreover, Linc01833 via regulation of miR$519 \mathrm{e}-3 \mathrm{p} / \mathrm{S} 100 \mathrm{~A} 4$ axis could enhance progression of lung cancer (25).

Table 4 shows S100A4-interacting lncRNAs.

\section{NON-CODING RNAs AND S100A7}

S100A7 is another member of the S100 family of proteins which contains 2 EF-hand domains. S100A7 differs from the other 


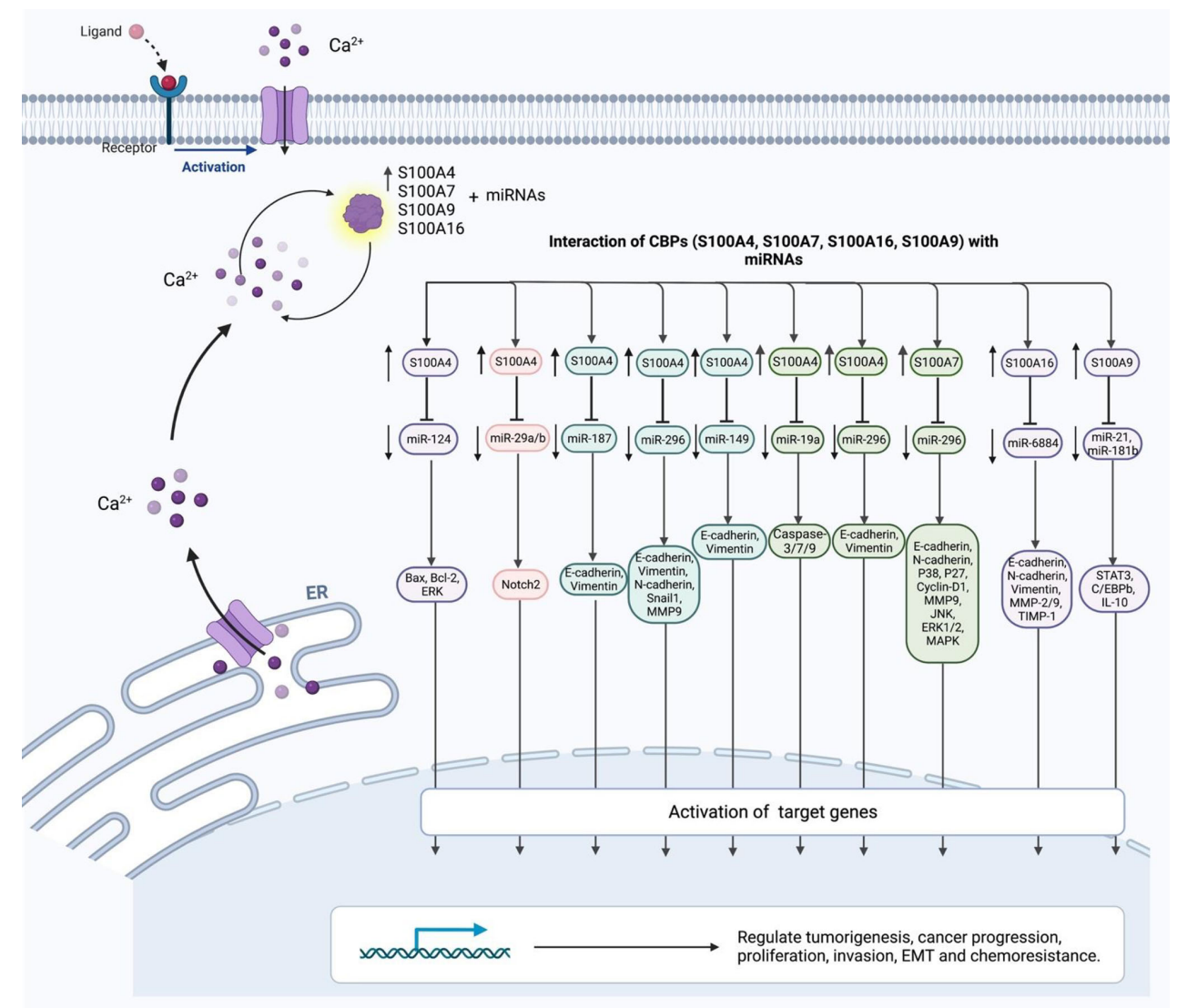

FIGURE 3 | The interaction of CBPs (S100A4, S100A7, S100A16, S100A9) with miRNAs.

members of this family in the absence of calcium binding capacity in one of its EF-hand domains, which is located at the $\mathrm{N}$-terminus. S100A7 has been shown to regulate metastatic ability of ovarian cancer cells and chemoresistance phenotype through modulation of MAPK pathway (Figure 3). This CBP has been shown to be targeted by miR-330-5p (26). Moreover, S100A7 has been found to be a direct target of miR-26b-5p. In fact, miR-26b-5p can suppress proliferation, migration and invasiveness of intrahepatic cholangiocarcinoma cells through deceasing expression of S100A7 (27). Table 5 shows S100A7interacting miRNAs.

\section{NON-CODING RNAs AND S100A1}

Similar to the majority of S100 proteins, binding of S100A1 with calcium results in great conformational alterations which facilitate interaction of this CBP with several protein targets. Targets of this CBP are those participating in calcium-related signal transduction, neurotransmitter release, cytoskeletal and filament associated proteins, transcription factors, a number of different proteins with enzymatic functions, and other CBPs, particularly S100B, S100A4 and S100P (28). Suppression of S100A1 expression has been suggested as a therapeutic modality for treatment of various disorders such as neurological disorders, diabetes mellitus, heart failure, and numerous kinds of malignancies (28). FOXD2-AS1 is the only lncRNA whose interactions with S100A1 have been verified. This lncRNA through modulation of S100A1/Hippo (29) and miR363-5p/S100A1 pathways (30) can participate in the pathogenesis of breast cancer and nasopharyngeal carcinoma, respectively (Table 6).

\section{NON-CODING RNAs AND S100P}

$\mathrm{S} 100 \mathrm{P}$ is another member of S100 CBPs that mediate calciumdependent signal transduction (31). S100P has been primarily isolated from the placenta (32). From an evolutionary point of view, S100P is regarded as a novel gene, existing only in the vertebrate genomes (33). As S100P is expressed in the uterus during the rhythmic hormonal changes, it might be associated with embryonic implantation/development (33). Yet, the role of S100P has been mostly investigated in the context of cancer (33). Two independent studies have assessed association between S100P and non-coding RNAs in pancreatic cancer. First, miR495 has been shown to suppress pancreatic carcinogenesis by targeting S100P (34). Secondly, circ_0092314 has been shown to 
TABLE 3 | S100A4-interacting miRNAs.

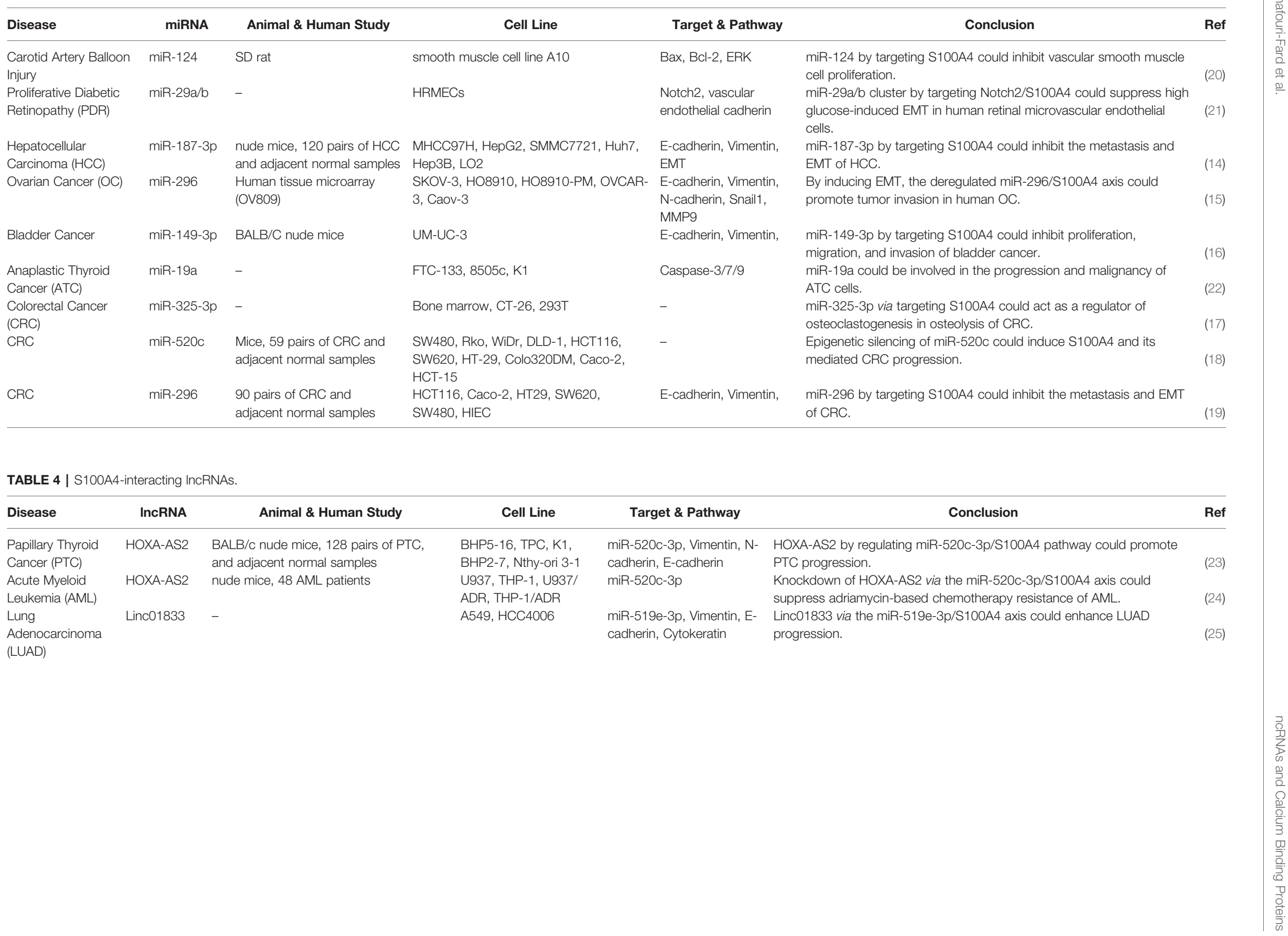


TABLE 5 | S100A7-interacting miRNAs.

Disease

miRNA

Animal \& Human Study

Cell Line

Target \& Pathway

Conclusion

Ovarian Cancer (OC) miR-330-5p 40 EOC tissues and 10 normal

Caov3, SKOV3,

E-cadherin, N-cadherin, P38, P27, Cyclin-

S100A7 via MAPK signaling could regulate OC cell metastasis

epithelial ovarian tissues

Caov3/Cis, SKOV3/Cis D1, MMPG, JNK, ERK1/2, MAPK

and chemoresistance.

Intrahepatic

miR-26b-5p 20 pairs of ICC and adjacent

RBE, HCCC-9810

miR-26b-5p by targeting S100A7 could regulate cel

proliferation, invasion, and metastasis in human ICC.

TABLE 6 | S100A1-interacting IncRNAs.

\begin{tabular}{|c|c|c|c|c|c|c|}
\hline Disease & IncRNA & Animal \& Human Study & Cell Line & Target \& Pathway & Conclusion & Ref \\
\hline $\begin{array}{l}\text { Breast Cancer } \\
\text { (BCa) }\end{array}$ & FOXD2-AS1 & BALB/c nude mice, Dataset & $\begin{array}{l}\text { MCF-10A, MCF-7, BT-549, } \\
\text { MDA-MB-468, MDA-MB-453 }\end{array}$ & $\begin{array}{l}\text { Cyclin-E1, CDK2, p21, MMP2/9, } \\
\text { YAD, LATS1, MST1/2, Hippo }\end{array}$ & $\begin{array}{l}\text { FOXD2-AS1 via the } S 100 A 1 / H i p p o \text { signaling pathway could } \\
\text { regulate the tumorigenesis and progression of } B C a \text {. }\end{array}$ & (29) \\
\hline $\begin{array}{l}\text { Nasopharyngeal } \\
\text { Carcinoma (NPC) }\end{array}$ & FOXD2-AS1 & $\begin{array}{l}\text { BALB/c nude mice, } 50 \text { pairs of NPC } \\
\text { and adjacent normal samples }\end{array}$ & $\begin{array}{l}\text { SUNE-1, CNE-1-2, HNE-1, } \\
\text { C666-1, HONE-1 }\end{array}$ & $m i R-363-5 p$ & $\begin{array}{l}\text { FOXD2-AS1, by modulating miR-363-5p/S100A1 pathway, } \\
\text { could participate in NPC carcinogenesis. }\end{array}$ & (30) \\
\hline
\end{tabular}


induce EMT in this type of cancer through sponging miR-671 and releasing S100P from its inhibitory effects (35). Table 7 shows S100P-ineracting miRNAs and circRNAs.

\section{NON-CODING RNAS AND OTHER CALCIUM BINDING PROTEINS}

S100A8, S100A9, S100A10, S100A11, S100A14, S100A16, NECAB3 and SMOC2 are other CBPs whose interactions with non-coding RNAs have been verified in the context of human disorders (Tables 8 and 9). LINC00174 via targeting regulates miR-320/S100A10 axis could increase malignant phenotypes (40). SNHG8 is another lncRNA which serves as a sponge for miR-1270 to up-regulate expression of S100A11 and promote progression of ovarian cancer (41). In the context of lung cancer, CASC9 has been found to sponge miR-335-3p and induce expression of S100A14 (42). In addition, GNAS-AS1 serves as a sponge for miR-4319 to increase expression of NECAB3 and regulate macrophage polarization (43).

\section{DISCUSSION}

The interactions between ncRNAs and CBPs have been assessed in different contexts. Most of studies have been conducted in the context of cancer, where CBPs affect malignant features through a variety of mechanisms, particularly induction of EMT. CAB39 is among the mostly assessed CBPs in this regard. Notably, the functional effect of CAB39-interacting miRNAs on the cells is largely mediated through modulation of activity of AMPK/ mTOR. S100A4 as another CBP has been shown to affect expression of EMT-markers such as E-cadherin, Vimentin, Ncadherin and Snaill. A number of miRNAs such as miR-187-3p, miR-296, miR-149-3p, miR-19a, miR-325-3p, miR-520c and miR-296 have been shown to affect carcinogenesis through modulation of expression of S100A4. Thus, S100A4-interacting non-coding RNAs are putative targets for design of novel therapeutic options against tumor metastasis and EMT. S100P and S100A16 are other CBPs whose interactions with noncoding RNAs are implicated in the process of EMT. In fact, miRNAs that affect expression of CBPs have been shown to bind with 3' UTR of mRNAs coding for CBPs.

circRNAs and lncRNAs that affect expression of CBPs mainly act as molecular sponges for miRNAs. For instance, circGSK3B/ miR-1265/CAB39, circ_0092314/miR-671/S100P, HOXA-AS2/ miR-520c-3p/S100A4, HOXA-AS2/miR-520c-3p/S100A4, Linc01833/miR-519e-3p/S100A4, LINC00174/miR-320/ S100A10, SNHG8/miR-1270/S100A11, CASC9/miR-335-3p/ S100A14 and GNAS-AS1/miR-4319/NECAB3 are examples of these regulatory axes which are involved in the pathoetiology of human disorders, particularly cancers.

The regulatory effects of some miRNAs on their specific CBPs have been verified in different contexts. For instance, the inhibitory impact of miR-451 on CAB39 has been shown to be implicated in drug-associated cardiac toxicity as well as lung

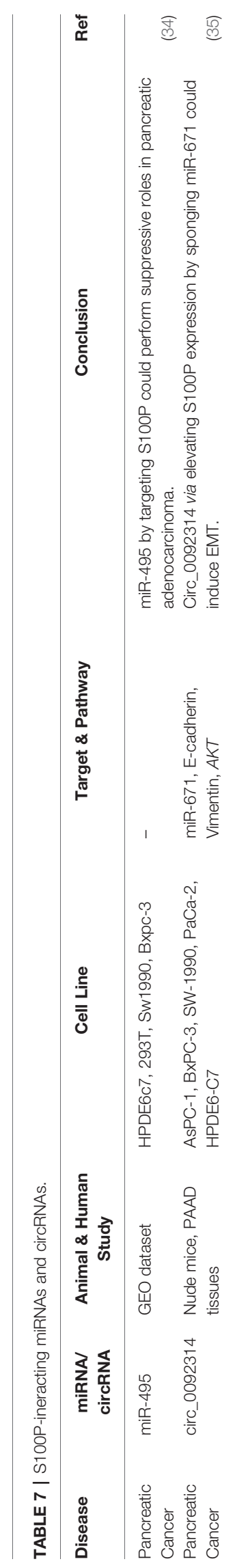


TABLE 8 | miRNAs interacting with other calcium binding proteins.

\begin{tabular}{|c|c|c|c|c|c|c|}
\hline Disease & miRNA & $\begin{array}{l}\text { Calcium } \\
\text { Binding } \\
\text { Pr. }\end{array}$ & $\begin{array}{l}\text { Animal \& Human } \\
\text { Study }\end{array}$ & Cell Line & Target \& Pathway & Conclusion \\
\hline $\begin{array}{l}\text { Endometrial } \\
\text { Carcinoma (EC) }\end{array}$ & miR-24 & S100A8 & $\begin{array}{l}46 \text { pairs of } E C \text { and } \\
\text { adjacent normal } \\
\text { samples }\end{array}$ & $\begin{array}{l}\text { HEC-1A, 293T, HEC-1A } \\
\text { Pax }\end{array}$ & - & $\begin{array}{l}\text { miR-24 by targeted silencing of the S100A8 gene could act as a tumor- } \\
\text { suppressing gene and increase chemotherapy sensitivity of EC cells to } \\
\text { paclitaxel. }\end{array}$ \\
\hline Chronic Sepsis & $\begin{array}{l}\text { miR-21, miR- } \\
181 b\end{array}$ & S100A9 & $\begin{array}{l}\text { C57BL/6N S100a9 } \\
\text { knockout mice }\end{array}$ & Gr1+CD11b+ & STAT3, C/EBPb, IL-10 & $\begin{array}{l}\text { S100A9 by inducing both miR-181b and miR-21 could maintain myeloid- } \\
\text { derived suppressor cells in chronic sepsis. }\end{array}$ \\
\hline $\begin{array}{l}\text { Gastric Cancer } \\
\text { (GC) }\end{array}$ & miR-6884-5p & S100A16 & $\begin{array}{l}30 \text { pairs of } \mathrm{GC} \text { and } \\
\text { adjacent normal } \\
\text { samples }\end{array}$ & $\begin{array}{l}\text { AGS, MKN45, BGC-823, } \\
\text { SGC-7901, MGC-803, } \\
\text { FTE187 }\end{array}$ & $\begin{array}{l}\text { E-cadherin, N-cadherin, } \\
\text { Vimentin, MMP-2/9, TIMP-1 }\end{array}$ & $\begin{array}{l}\text { miR-6884-5p by targeting S100A16 could regulate proliferation, invasion, } \\
\text { and EMT of GC cells. }\end{array}$ \\
\hline Glomerulonephritis & miR-17-5p & SMOC2 & - & $\mathrm{AB} 8 / 13$ & $\begin{array}{l}\text { NF-kB, TGF } \beta 1 \text {, Fibronectin-1, } \\
\text { Collagen-1/II, } \alpha \text {-SMA, SMAD- } \\
2 / 3\end{array}$ & $\begin{array}{l}\text { miR-17-5p by suppressing SMOC2 via the NF- } \mathrm{KB} \text { and TGF } \beta \text { signaling } \\
\text { could restrain the dysfunction of Ang-II induced podocytes. }\end{array}$ \\
\hline
\end{tabular}

TABLE 9 | IncRNAs interacting with other calcium binding-proteins

\begin{tabular}{|c|c|c|c|c|c|c|c|}
\hline Disease & IncRNA & $\begin{array}{l}\text { Calcium } \\
\text { Binding Pr. }\end{array}$ & Animal \& Human Study & Cell Line & Target \& Pathway & Conclusion & Ref \\
\hline $\begin{array}{l}\text { Hepatocellular } \\
\text { Carcinoma (HCC) }\end{array}$ & LINC00174 & S100A10 & $\begin{array}{l}45 \text { pairs of } \mathrm{HCC} \text { and } \\
\text { adjacent normal samples }\end{array}$ & $\begin{array}{l}\text { Hep3B, Huh7, SMMC-7721, } \\
\text { L02 }\end{array}$ & miR-320 & $\begin{array}{l}\text { LINC00174 via targeting regulates miR-320/S100A10 axis could } \\
\text { increase malignant phenotypes. }\end{array}$ & (40) \\
\hline Ovarian Cancer (OC) & SNHG8 & S100A11 & $\begin{array}{l}\text { Mice, } 19 \text { pairs of } \mathrm{OC} \text { and } \\
\text { adjacent normal samples }\end{array}$ & $\begin{array}{l}\text { IOSE, A2780, HOSE 11-12, } \\
\text { SKOV3, HO8910, OVCAR3 }\end{array}$ & $m i R-1270$ & $\begin{array}{l}\text { SNHG8 via serving as a sponge for miR-1270 to regulate S100A11 } \\
\text { could promote OC progression. }\end{array}$ & (41) \\
\hline $\begin{array}{l}\text { Non-small cell lung } \\
\text { cancer (NSCLC) }\end{array}$ & CASC9 & S100A14 & $\begin{array}{l}43 \text { pairs of NSCLC and } \\
\text { adjacent normal samples }\end{array}$ & A549, H1299, BEAS-2B & $\begin{array}{l}\text { miR-335-3p, MMP-2/9, } \\
\text { N-cadherin, E-cadherin }\end{array}$ & $\begin{array}{l}\text { Upregulation of CASC9 via inhibiting miR-335-3p and activating } \\
\text { S100A14 could contribute to the progression of NSCLC. }\end{array}$ & (42) \\
\hline NSCLC & GNAS-AS1 & NECAB3 & $\begin{array}{l}50 \text { pairs of NSCLC and } \\
\text { adjacent normal samples }\end{array}$ & $\begin{array}{l}\text { PC9, SPCA1, H358, A549, } \\
\text { H1299, 16HBE }\end{array}$ & miR-4319, IL-10, Arg-1 & $\begin{array}{l}\text { GNAS-AS1/miR-4319/NECAB3 axis by altering macrophage } \\
\text { polarization could promote migration and invasion of NSCLC cells. }\end{array}$ & (43) \\
\hline
\end{tabular}


cancer. Similarly, CAB39 has been found as a target of miR-107 in both osteoblasts and colorectal cancer cells. Finally, S100A4 has been shown to be targeted by miR-296 in both ovarian and colorectal cancer cells. For other miRNAs, regulatory effects have been confirmed only in a single context.

Taken together, several miRNAs, IncRNAs and circRNAs can regulate expressions of CBPs and participate in the etiology of human disorders via this route. Identification of this type of interactions has practical significance in design of disorders which are associated with abnormal calcium signal transduction. Research in this field is still in its infancy and the

\section{REFERENCES}

1. Yáñez M, Gil-Longo J, Campos-Toimil M. Calcium Binding Proteins. Adv Exp Med Biol (2012) 740:461-82. doi: 10.1007/978-94-007-2888-2_19

2. Hiraoki T, Vogel HJ. Structure and Function of Calcium-Binding Proteins. J Cardiovasc Pharmacol (1987) 10:S14-31. doi: 10.1097/00005344-198710001-00004

3. Boudeau J, Baas AF, Deak M, Morrice NA, Kieloch A, Schutkowski M, et al. MO25alpha/beta Interact With STRADalpha/beta Enhancing Their Ability to Bind, Activate and Localize LKB1 in the Cytoplasm. EMBO J (2003) 22 (19):5102-14. doi: 10.1093/emboj/cdg490

4. Li J, Wan W, Chen T, Tong S, Jiang X, Liu W. miR-451 Silencing Inhibited Doxorubicin Exposure-Induced Cardiotoxicity in Mice. BioMed Res Int (2019) 2019:E collection. doi: 10.1155/2019/1528278

5. Zhuang Y, Wang S, Fei H, Ji F, Sun P. miR-107 Inhibition Upregulates CAB39 and Activates AMPK-Nrf2 Signaling to Protect Osteoblasts From Dexamethasone-Induced Oxidative Injury and Cytotoxicity. Aging (Albany NY) (2020) 12(12):11754. doi: 10.18632/aging.103341

6. Jiang W-L, Zhao K-C, Yuan W, Zhou F, Song H-Y, Liu G-L, et al. MicroRNA31-5p Exacerbates Lipopolysaccharide-Induced Acute Lung Injury via Inactivating Cab39/Ampk $\alpha$ Pathway. Oxidative Medicine and Cellular Longevity (2020) 2020. doi: 10.1155/2020/8822361

7. Xu Z, Li Z, Wang W, Xia Y, He Z, Li B, et al. MIR-1265 Regulates Cellular Proliferation and Apoptosis by Targeting Calcium Binding Protein 39 in Gastric Cancer and, Thereby, Impairing Oncogenic Autophagy. Cancer Lett (2019) 449:226-36. doi: 10.1016/j.canlet.2019.02.026

8. Liang Y, Zhu D, Hou L, Wang Y, Huang X, Zhou C, et al. MiR-107 Confers Chemoresistance to Colorectal Cancer by Targeting Calcium-Binding Protein 39. Br J Cancer (2020) 122(5):705-14. doi: 10.1038/s41416-019-0703-3

9. Wang H-M, Lu Y-J, He L, Gu N-J, Wang S-Y, Qiu X-S, et al. HPV16 E6/E7 Promote the Translocation and Glucose Uptake of GLUT1 by PI3K/AKT Pathway via Relieving miR-451 Inhibitory Effect on CAB39 in Lung Cancer Cells. Ther Adv Chronic Dis (2020) 11:2040622320957143. doi: 10.1177/2040622320957143

10. Zhang S, Zhang R, Qiao P, Ma X, Lu R, Wang F, et al. Metformin-Induced MicroRNA-34a-3p Downregulation Alleviates Senescence in Human Dental Pulp Stem Cells by Targeting CAB39 Through the AMPK/mTOR Signaling Pathway. Stem Cells Int (2021) 2021:E collection. doi: 10.1155/2021/6616240

11. Li K, Cao J, Zhang Z, Chen K, Ma T, Yang W, et al. Circular RNA Circgsk3b Promotes Cell Proliferation, Migration, and Invasion by Sponging miR-1265 and Regulating CAB39 Expression in Hepatocellular Carcinoma. Front Oncol (2020) 10:598256. doi: 10.3389/fonc.2020.598256

12. Meng K, Jiao J, Zhu R-R, Wang B-Y, Mao X-B, Zhong Y-C, et al. The Long Noncoding RNA Hotair Regulates Oxidative Stress and Cardiac Myocyte Apoptosis During Ischemia-Reperfusion Injury. Oxid Med Cell Longevity (2020) 2020:E collection. doi: 10.1155/2020/1645249

13. Engelkamp D, Schäfer BW, Mattei MG, Erne P, Heizmann CW. Six S100 Genes Are Clustered on Human Chromosome 1q21: Identification of Two Genes Coding for the Two Previously Unreported Calcium-Binding Proteins S100D and S100E. Proc Natl Acad Sci USA (1993) 90(14):6547-51. doi: 10.1073/pnas.90.14.6547

14. Dou C, Liu Z, Xu M, Jia Y, Wang Y, Li Q, et al. miR-187-3p Inhibits the Metastasis and Epithelial-Mesenchymal Transition of Hepatocellular Carcinoma by Targeting S100A4. Cancer Lett (2016) 381(2):380-90. doi: 10.1016/j.canlet.2016.08.011 functional associations between non-coding RNAs and several members of CBP family need to be clarified.

\section{AUTHOR CONTRIBUTIONS}

SG-F wrote the draft and revised it. MT and $\mathrm{AB}$ designed and supervised the study. $\mathrm{HS}, \mathrm{JM}, \mathrm{BH}$, and $\mathrm{HH}$ collected the data and designed the figures and tables. All the authors read and approved the submitted version.
15. Yan W, Chen J, Chen Z, Chen H. Deregulated miR-296/S100A4 Axis Promotes Tumor Invasion by Inducing Epithelial-Mesenchymal Transition in Human Ovarian Cancer. Am J Cancer Res (2016) 6(2):260.

16. Yang D, Du G, Xu A, Xi X, Li D. Expression of miR-149-3p Inhibits Proliferation, Migration, and Invasion of Bladder Cancer by Targeting S100A4. Am J Cancer Res (2017) 7(11):2209.

17. Chengling L, Yulin Z, Xiaoyu X, Xingchen L, Sen Z, Ziming W, et al. miR-3253 p, a Novel Regulator of Osteoclastogenesis in Osteolysis of Colorectal Cancer Through Targeting S100A4. Mol Med (2021) 27(1):1-10. doi: 10.1186/s10020021-00282-7

18. Mudduluru G, Ilm K, Fuchs S, Stein U. Epigenetic Silencing of miR-520c Leads to Induced S100A4 Expression and Its Mediated Colorectal Cancer Progression. Oncotarget (2017) 8(13):21081. doi: 10.18632/oncotarget.15499

19. Zhang R, Guo Y, Ma Z, Ma G, Xue Q, Li F, et al. Long non-Coding RNA PTENP1 Functions as a ceRNA to Modulate PTEN Level by Decoying miR$106 \mathrm{~b}$ and miR-93 in Gastric Cancer. Oncotarget (2017) 8(16):26079. doi: 10.18632/oncotarget.15317

20. Choe N, Kwon DH, Shin S, Kim YS, Kim YK, Kim J, et al. The Micro RNA miR-124 Inhibits Vascular Smooth Muscle Cell Proliferation by Targeting S100 Calcium-Binding Protein A4 (S100a4). FEBS Lett (2017) 591(7):104152. doi: 10.1002/1873-3468.12606

21. Zhang J, Zeng Y, Chen J, Cai D, Chen C, Zhang S, et al. Mir-29a/B Cluster Suppresses High Glucose-Induced Endothelial-Mesenchymal Transition in Human Retinal Microvascular Endothelial Cells by Targeting Notch2. Exp Ther Med (2019) 17(4):3108-16. doi: 10.3892/etm.2019.7323

22. Calabrese G, Dolcimascolo A, Caruso G, Forte S. miR-19a Is Involved in Progression and Malignancy of Anaplastic Thyroid Cancer Cells. OncoTargets Ther (2019) 12:9571. doi: 10.2147/OTT.S221733

23. Xia F, Chen Y, Jiang B, Du X, Peng Y, Wang W, et al. Long Noncoding RNA HOXA-AS2 Promotes Papillary Thyroid Cancer Progression by Regulating miR-520c-3p/S100A4 Pathway. Cell Physiol Biochem (2018) 50(5):1659-72. doi: 10.1159/000494786

24. Dong X, Fang Z, Yu M, Zhang L, Xiao R, Li X, et al. Knockdown of Long Noncoding RNA HOXA-AS2 Suppresses Chemoresistance of Acute Myeloid Leukemia via the miR-520c-3p/S100A4 Axis. Cell Physiol Biochem (2018) 51 (2):886-96. doi: 10.1159/000495387

25. Zhang Y, Li W, Lin Z, Hu J, Wang J, Ren Y, et al. The Long Noncoding RNA Linc01833 Enhances Lung Adenocarcinoma Progression via MiR-519e-3p/ S100A4 Axis. Cancer Manage Res (2020) 12:11157. doi: 10.2147/ CMAR.S279623

26. Lin M, Xia B, Qin L, Chen H, Lou G. S100A7 Regulates Ovarian Cancer Cell Metastasis and Chemoresistance Through MAPK Signaling and Is Targeted by miR-330-5p. DNA Cell Biol (2018) 37(5):491-500. doi: 10.1089/dna.2017.3953

27. Fan F, Lu J, Yu W, Zhang Y, Xu S, Pang L, et al. MicroRNA-26b-5p Regulates Cell Proliferation, Invasion and Metastasis in Human Intrahepatic Cholangiocarcinoma by Targeting S100A7. Oncol Lett (2018) 15(1):386-92. doi: $10.3892 / \mathrm{ol} .2017 .7331$

28. Wright NT, Cannon BR, Zimmer DB, Weber DJ. S100A1: Structure, Function, and Therapeutic Potential. Curr Chem Biol (2009) 3(2):138-45. doi: $10.2174 / 2212796810903020138$

29. Huang P, Xue J. Long non-Coding RNA FOXD2-AS1 Regulates the Tumorigenesis and Progression of Breast Cancer via the S100 Calcium 
Binding Protein A1/Hippo Signaling Pathway. Int J Mol Med (2020) 46 (4):1477-89. doi: 10.3892/ijmm.2020.4699

30. Chen G, Sun W, Hua X, Zeng W, Yang L. Long Non-Coding RNA FOXD2AS1 Aggravates Nasopharyngeal Carcinoma Carcinogenesis by Modulating miR-363-5p/S100A1 Pathway. Gene (2018) 645:76-84. doi: 10.1016/ j.gene.2017.12.026

31. Donato R. S100: A Multigenic Family of Calcium-Modulated Proteins of the EF-Hand Type With Intracellular and Extracellular Functional Roles. Int J Biochem Cell Biol (2001) 33(7):637-68. doi: 10.1016/S1357-2725(01)00046-2

32. Becker T, Gerke V, Kube E, Weber K. S100P, a Novel Ca2+-Binding Protein From Human Placenta: cDNA Cloning, Recombinant Protein Expression and Ca2+ Binding Properties. Eur J Biochem (1992) 207(2):541-7. doi: 10.1111/ j.1432-1033.1992.tb17080.x

33. Prica F, Radon T, Cheng Y, Crnogorac-Jurcevic T. The Life and Works of S100P - From Conception to Cancer. Am J Cancer Res (2016) 6(2):562-76. doi: 10.1016/j.pan.2016.04.011

34. Jiang PF, Zhang XJ, Song CY, Zhang YX, Wu Y. S100P Acts as a Target of miR-495 in Pancreatic Cancer Through Bioinformatics Analysis and Experimental Verification. Kaohsiung J Med Sci (2021) 37(7):562-71. doi: $10.1002 / \mathrm{kjm} 2.12383$

35. Shen Q, Zheng G, Zhou Y, Tong J, Xu S, Gao H, et al. CircRNA Circ_0092314 Induces Epithelial-Mesenchymal Transition of Pancreatic Cancer Cells via Elevating the Expression of S100P by Sponging miR-671. Front Oncol (2021) 11:986. doi: 10.3389/fonc.2021.675442

36. Lang B, Shang C, Meng L-r. Targeted Silencing of S100A8 Gene by miR-24 to Increase Chemotherapy Sensitivity of Endometrial Carcinoma Cells to Paclitaxel. Med Sci monitor: Int Med J Exp Clin Res (2016) 22:1953. doi: 10.12659/MSM.899179

37. Alkhateeb T, Kumbhare A, Bah I, Youssef D, Yao ZQ, McCall CE, et al. S100A9 Maintains Myeloid-Derived Suppressor Cells in Chronic Sepsis by Inducing miR-21 and miR-181b. Mol Immunol (2019) 112:72-81. doi: 10.1016/j.molimm.2019.04.019

38. Lv H, Hou H, Lei H, Nie C, Chen B, Bie L, et al. MicroRNA-6884-5p Regulates the Proliferation, Invasion, and EMT of Gastric Cancer Cells by Directly Targeting S100a16. Oncol Res (2020) 28(3):225. doi: 10.3727/ 096504019X15753718797664
39. Xu M, Yi M, Li N. MicroRNA-17-5p Restrains the Dysfunction of Ang-II Induced Podocytes by Suppressing Secreted Modular Calcium-Binding Protein 2 via NF-kb and Tgf $\beta$ Signaling. Environ Toxicol (2021) 36 (7):1402-11. doi: 10.1002/tox.23136

40. Zhao JT, Chi BJ, Sun Y, Chi NN, Zhang XM, Sun JB, et al. LINC00174 Is an Oncogenic lncRNA of Hepatocellular Carcinoma and Regulates miR-320/ S100A10 Axis. Cell Biochem Funct (2020) 38(7):859-69. doi: 10.1002/cbf.3498

41. Xuan L, Sun Z, Wang J, Gao S. IncRNA SNHG8 Promotes Ovarian Cancer Progression Through Serving as Sponge for miR-1270 to Regulate S100A11 Expression. J Gene Med (2021) 25::e3315. doi: 10.1002/jgm.3315

42. Zhao W, Chen T, Zhao Y. Upregulated IncRNA CASC9 Contributes to Progression of Non-Small Cell Lung Cancer Through Inhibition of miR335-3p and Activation S100A14 Expression. OncoTargets Ther (2020) 13:6027. doi: 10.2147/OTT.S249973

43. Li Z, Feng C, Guo J, Hu X, Xie D. GNAS-AS1/miR-4319/NECAB3 Axis Promotes Migration and Invasion of Non-Small Cell Lung Cancer Cells by Altering Macrophage Polarization. Funct Integr Genomics (2020) 20(1):17-28. doi: 10.1007/s10142-019-00696-x

Conflict of Interest: The authors declare that the research was conducted in the absence of any commercial or financial relationships that could be construed as a potential conflict of interest.

Publisher's Note: All claims expressed in this article are solely those of the authors and do not necessarily represent those of their affiliated organizations, or those of the publisher, the editors and the reviewers. Any product that may be evaluated in this article, or claim that may be made by its manufacturer, is not guaranteed or endorsed by the publisher.

Copyright (c) 2022 Ghafouri-Fard, Majidpoor, Shoorei, Hussen, Hadayat Jamal, Baniahmad, Taheri and Mokhtari. This is an open-access article distributed under the terms of the Creative Commons Attribution License (CC BY). The use, distribution or reproduction in other forums is permitted, provided the original author(s) and the copyright owner(s) are credited and that the original publication in this journal is cited, in accordance with accepted academic practice. No use, distribution or reproduction is permitted which does not comply with these terms. 